\title{
Pattern and Determinant of Contraceptive Use among Women in Indonesia from 2007 to 2017: Evidence from Demographic and Health Survey
}

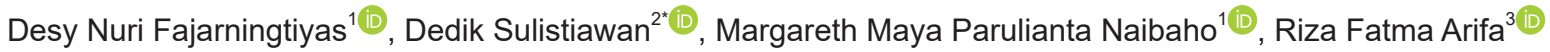 \\ ${ }^{1}$ National Population and Family Planning Board, Jakarta, Indonesia; ${ }^{2}$ Department of Public Health, Universitas Ahmad Dahlan, \\ Yogyakarta Indonesia; ${ }^{3}$ National Population and Family Planning Board, Yogyakarta, Indonesia
}

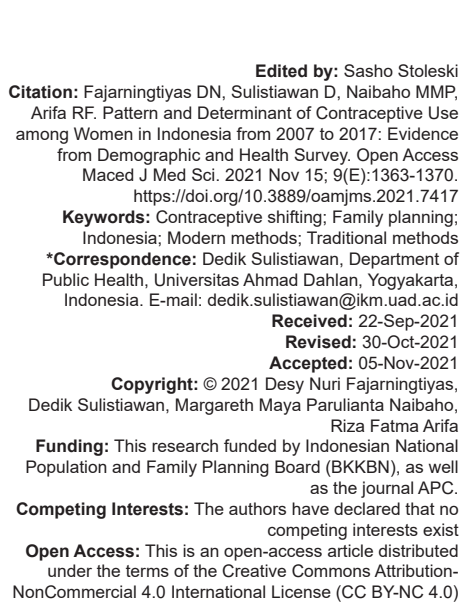

\section{Introduction}

Family planning (FP) and contraception are deliberately used to help individuals prevent unintended pregnancies and improve maternal health. Using contraceptives will enhance the health, economic and social facets of life for individuals, i.e., reducing genderbased violence, improving women's employment opportunities, increasing awareness, and building good decision-making [1]. Therefore, the international community advocates for FP to become a priority in the Sustainable Development Goals agenda because of its potential to contribute to global sustainable development [2], [3].

The London Summit on FP sets the target of delivering successful FP awareness and resources to an additional 120 million women and girls by the year 2020. With FP2020, commitments have been made by national governments, civil society, and the private sector to resolve the many barriers to supply and demand affecting access to and use of contraception [4]. Indicators on modern contraception utilization as the most effective methods were introduced to track the target achievements. Modern contraceptive methods (such as female sterilization, male sterilization, intrauterine device, implants, injections methods, pills, condoms, emergency contraception, diaphragm, and lactational amenorrhea method) have become more widely used and believed to be more effective than traditional methods (such as periodic abstinence, withdrawal, and folkloric methods) [5]. Thus, decision-makers promote modern methods in many countries [4], [5], [6].

The FP program in Indonesia is aimed to increase the prevalence of modern contraceptive methods [7]. Over the past decade, however, the prevalence of the unmet need for modern methods has persisted. According to the Performance Monitoring and 
Accountability 2020 survey, the prevalence of unmet needs for modern methods increased to $14.4 \%$ in 2015 [8]. Besides, the contraceptive discontinuation rate is also still relatively high [9]. Indonesian Demographic and Health Survey (IDHS) 2017 reported contraceptive discontinuation rate reaches $34 \%$, with the most frequent reason is because of the side effect [10].

In contrast to the global trends, traditional contraceptives (i.e., periodic abstinence and withdrawal) in Indonesia have increased steadily in the past decade. IDHS 2017 reported that traditional methods among married women are about $6.4 \%$, slightly increased from previous surveys [10]. These methods are less effective than modern ones if they are not used with conscience and practical skills [6].

Many studies discuss the use of contraception in Indonesia [7], [11], [12], [13], [14], [15]. However, most of the research conducted in this area discusses contraceptive use determinants without distinguishing the respondents' contraception type [11], [12]. Some of them studied contraceptive use patterns by classifying modern and traditional contraceptives [7], analyzed patterns of use of long-term methods [13], and others discussed the shift in contraceptive use [14], [15]. Meanwhile, research that examines contraceptive use patterns based on more specific contraception types in Indonesia, i.e., long-term, short-term, and traditional contraception, is still limited. Most of the existing studies analyzed contraceptive use simultaneously and did not focus on investigating the shifting patterns over the periods.

On the other hand, the pattern of contraceptive use from time to time is not always the same, nor are the factors that influence it. Determinants of contraceptive use such as socio-economic conditions, knowledge, and matters related to service provision are usually dynamic, influenced by various factors set by the government, which sometimes change accordingly with circumstances. This study aimed to analyze contraceptive use patterns and determinants according to the type of contraception, such as long term (tubectomy, vasectomy, implant, and intrauterine device), short term (injections, pills, condoms, and other modern devices), and traditional (withdrawal, periodic/ calendar abstinence, herbal medicine, massage, and other traditional contraceptives) during the past 10 years, from 2007 to 2017 .

\section{Methods}

\section{Data source}

The data used in this study was the dataset of 2007, 2012, and 2017 IDHS in the individual records section. MEASURE DHS granted permission to access and use the datasets. It was available for free from https://dhsprogram.com. In this study, the analysis unit was women aged 15-49 years who were married/ living together with a partner and used contraception. This study involved 18,934 women from IDHS 2007; 20,361 women from IDHS 2012; and 22,590 women from IDHS 2017.

\section{Variable}

The dependent variable in this study was the use of contraception when the survey was conducted. Contraceptive use was categorized into three groups, women who use long-term modern contraception (tubectomy, vasectomy, implant, and intrauterine device); women who use modern short-term contraceptives (injections, pills, condoms, and other modern devices), and traditional contraceptives (withdrawal, periodic/ calendar abstinence, herbal medicine, massage, and other traditional contraceptives).

This study's independent variables were educational attainment, household wealth index, place of residence, knowledge of contraception (the number of known contraceptive methods and types), fertility intention, knowledge of the ovulation cycle, number of live children, age, and region. This variable was deliberately chosen because it was thought to be the main factor associated with contraceptive use, and it was essential to determine contraceptive use patterns over time.

\section{Statistical analysis}

The univariate analysis was used to assess the percent distribution of each variable on all batch surveys. We create a time variable with a dummy for 2012 and 2017, whereas 2007 was used as the baseline or reference. After that, we continue to generate an interaction variable between the dummy time variable and each independent variable. Multinomial pooled logistic regression analysis with time interaction was applied to determine the shifting patterns of the independent variables related to contraceptive use over time. According to the IDHS reports' recommendations for each batch, descriptive statistics, and regression models were presented with a complex sample weighting. Data were analyzed using STATA version 16.0 .

\section{Ethics statement}

As the study entailed secondary analysis of data containing no personally identifying information, a waiver was granted by the Inner-City Fund institutional review board, a global advisory, and digital services provider that implements Demographic and Health Surveys (DHS) programs. 


\section{Results}

\section{Characteristics of married women}

Individual data that have analyzed were collected from 18,934 women in 2007, 20,361 women in 2012 , and 22,590 women in 2017 , for a total of 61,885 women. The sociodemographic characteristics of respondents in this study are presented in Table 1. Most respondents were between the ages of 30 and 39 and were classified as having a middle-richer household wealth index. Respondents were slightly more distributed in the rural area. Furthermore, Table 1 reveals that women's educational attainment has shifted. Low-educated women dominated in 2007. Secondary and higher-educated women, on the other hand, increased slightly in 2012. It showed that Indonesian women's educational attainment was improving year after year.

Table 1: Percentage distribution of sample characteristics of women who use any contraceptive use

\begin{tabular}{|c|c|c|c|c|c|c|}
\hline \multirow[t]{3}{*}{$\begin{array}{l}\text { Variable } \\
\text { nat }\end{array}$} & \multicolumn{6}{|c|}{ Period of Observations } \\
\hline & \multicolumn{2}{|c|}{2007} & \multicolumn{2}{|l|}{2012} & \multicolumn{2}{|l|}{2017} \\
\hline & $\mathrm{n}$ & $\%$ & $\mathrm{n}$ & $\%$ & $\mathrm{n}$ & $\%$ \\
\hline \multicolumn{7}{|l|}{ Educational attainment } \\
\hline No education & 845 & 4.5 & 515 & 2.5 & 243 & 1.1 \\
\hline Primary & 8,834 & 46.7 & 8,048 & 39.5 & 7,920 & 35.1 \\
\hline Secondary & 7,908 & 41.8 & 9,942 & 48.8 & 11,960 & 52.9 \\
\hline Higher & 1,347 & 7.1 & 1,855 & 9.1 & 2,467 & 10.9 \\
\hline \multicolumn{7}{|l|}{ Household wealth index } \\
\hline Poor & 6,994 & 36.9 & 7,462 & 36.7 & 8,486 & 37.6 \\
\hline Middle & 3,951 & 20.9 & 4,307 & 21.2 & 4,824 & 21.4 \\
\hline Rich & 7,989 & 42.2 & 8,592 & 42.2 & 9,280 & 41.1 \\
\hline \multicolumn{7}{|l|}{ Place of residence } \\
\hline Urban & 7,993 & 42.2 & 10,063 & 49.4 & 10,822 & 47.9 \\
\hline Rural & 10,941 & 57.8 & 10,297 & 50.6 & 11,768 & 52.1 \\
\hline \multicolumn{7}{|l|}{ Knowledge of contraception } \\
\hline Lack (less than 8 methods) & 8,011 & 42.3 & 7,550 & 37.1 & 6,731 & 29.8 \\
\hline Better (at least 8 methods) & 10,923 & 57.7 & 12,811 & 62.9 & 15,860 & 70.2 \\
\hline \multicolumn{7}{|l|}{ Fertility intention } \\
\hline Wants more children & 7,068 & 37.3 & 7,770 & 38.2 & 7,603 & 33.7 \\
\hline Undecided & 672 & 3.5 & 940 & 4.6 & 732 & 3.2 \\
\hline Wants no more children & 11,195 & 59.1 & 11,651 & 57.2 & 14,255 & 63.1 \\
\hline \multicolumn{7}{|l|}{ Knowledge of ovulation cycles } \\
\hline Incorrect & 15,193 & 80.2 & 16,490 & 81.0 & 17,527 & 77.6 \\
\hline Correct & 3,741 & 19.8 & 3,871 & 19.0 & 5,063 & 22.4 \\
\hline \multicolumn{7}{|l|}{ Parity } \\
\hline $0-1$ & 5,185 & 27.4 & 5,689 & 27.9 & 5,426 & 24.0 \\
\hline $2-3$ & 10,815 & 57.1 & 11,985 & 58.9 & 14,494 & 64.2 \\
\hline$>3$ & 2,934 & 15.5 & 2,687 & 13.2 & 2,671 & 11.8 \\
\hline \multicolumn{7}{|l|}{ Age } \\
\hline $15-29$ & 6,380 & 33.7 & 6,403 & 31.4 & 5,648 & 25.0 \\
\hline $30-39$ & 7,878 & 41.6 & 8,284 & 40.7 & 9,478 & 42.0 \\
\hline $40-49$ & 4,676 & 24.7 & 5,674 & 27.9 & 7,465 & 33.0 \\
\hline \multicolumn{7}{|l|}{ Region } \\
\hline Other Islands & 6,551 & 34.6 & 7,467 & 36.7 & 8,468 & 37.5 \\
\hline Java-Bali & 12,383 & 65.4 & 12,894 & 63.3 & 14,122 & 62.5 \\
\hline Total & 18,934 & 100.0 & 20,361 & 100.0 & 22,590 & 100.0 \\
\hline
\end{tabular}

\section{The pattern of contraceptive use over time}

Figure 1 shows changes in trends in contraceptive use over time. In $2017,89.9 \%$ of currently married women in Indonesia who used contraception were users of modern contraceptives, and this pattern decreased by $3.6 \%$ from 2007. In general, during the three survey periods, contraceptive use was still dominated by short-term contraception, although over the past 5 years (2012-2017), the proportion has shown a decrease of around $9 \%$. The long-acting reversible contraception (LARC) usage rate, on the other hand, increased during the same period, though it remained relatively stable from 2007 to 2012. Interestingly, traditional contraceptive adoption followed the same patterns as LARC, although having a lower prevalence. Following a period of stagnation from 2007 to 2012, the proportion increased slightly in 2017.

\begin{tabular}{|c|c|c|c|}
\hline & IDHS 2007 (\%) & IDHS 2012 (\%) & IDHS $2017(\%)$ \\
\hline Implants/Norplant & 4.52 & 5.35 & 7.47 \\
\hline IUD & 7.98 & 6.33 & 7.4 \\
\hline Female Sterilization & 4.96 & 5.16 & 5.9 \\
\hline Male Sterilization & 0.35 & 0.25 & 0.27 \\
\hline Injections & 51.92 & 51.61 & 45.63 \\
\hline Pill & 21.59 & 21.93 & 19.1 \\
\hline Male Condom & 2.14 & 2.83 & 4 \\
\hline Lactational Amenorrhea (LAM) & 0.05 & 0.07 & 0.14 \\
\hline Other Modern Method & 0.24 & 0.01 & 0.03 \\
\hline Withdrawal & 3.39 & 3.75 & 6.64 \\
\hline Periodic Abstinence & 2.46 & 2.12 & 3 \\
\hline Other Traditional & 0.4 & 0.6 & 0.43 \\
\hline
\end{tabular}

Figure 1: Indonesian contraceptive method mix 2007-2017

Based on Table 2, almost all base period variables (2007) had a significant relationship with contraception choice, except the household wealth index. After 5 and 10 years of observations, some of these variables indicated various relationships with contraceptive use. It undoubtedly appeared that there was a change in the likelihood of using modern and traditional contraceptives triggered by several predictor variables.

In 2007, education levels were statistically unassociated with traditional contraceptive use. However, after 5 and 10 years of observation, there was a considerable shift in the pattern of traditional contraceptive use by level of education. Women with higher education levels were more than 1.5 times more likely to utilize traditional methods in the 2012 IDHS. In the following 5 years, this group had more than two times the probability of using traditional methods. On the other hand, an inconsistent pattern was observed for the use of the long-term method. The probability of using longterm methods was lower in women with higher education as the chances of using traditional methods increased after 10 years of observation. In the 2007 IDHS, highly educated women were more than twice as likely to use long-term contraception. However, in the next 10 years, the probability decreased to $<1.5$ times. It suggested that highly educated women were more likely to abandon modern contraceptive methods, both long and shortterm, and switched to traditional contraception.

An identical pattern occurred in contraceptive use according to the knowledge of contraceptive methods. Women who gained a profound understanding of contraceptives were more likely to practice traditional methods over time. At baseline observations, the odds ratio of the relationship between good contraceptive knowledge and the use of traditional contraceptives was around 2.65 , decreased in the next 5 years to approximately 2.24. However, in the 2017 IDHS, the odds ratio increased to 3.01 . The probability of using 
Table 2: Contraceptive use patterns over time based on sociodemographic variables in Indonesia during 2007-2017

\begin{tabular}{|c|c|c|c|c|c|c|c|c|c|c|c|c|}
\hline \multirow[t]{4}{*}{ Variable } & \multicolumn{4}{|c|}{ Main Effect } & \multicolumn{8}{|c|}{ Time Interaction } \\
\hline & \multicolumn{4}{|c|}{2007 (Baseline) } & \multicolumn{4}{|c|}{2012 (After 5 Years) } & \multicolumn{4}{|c|}{2017 (After 10 Years) } \\
\hline & \multicolumn{2}{|c|}{ Traditional } & \multicolumn{2}{|l|}{ LARC } & \multicolumn{2}{|c|}{ Traditional } & \multicolumn{2}{|l|}{ LARC } & \multicolumn{2}{|c|}{ Traditional } & \multicolumn{2}{|l|}{ LARC } \\
\hline & OR & $95 \% \mathrm{Cl}$ & OR & $95 \% \mathrm{Cl}$ & OR & $95 \% \mathrm{Cl}$ & OR & $95 \% \mathrm{Cl}$ & OR & $95 \% \mathrm{Cl}$ & OR & $95 \% \mathrm{Cl}$ \\
\hline \multicolumn{13}{|l|}{ Educational attainment } \\
\hline No education & 1 & $1.00,1.00$ & 1 & $1.00,1.00$ & 1 & $1.00,1.00$ & 1 & $1.00,1.00$ & 1 & $1.00,1.00$ & 1 & $1.00,1.00$ \\
\hline Primary & 0.75 & $0.46,1.22$ & 0.78 & $0.51,1.20$ & $0.45^{\star \star \star}$ & $0.32,0.63$ & $0.34^{\star * *}$ & $0.27,0.43$ & 0.77 & $0.58,1.03$ & $0.51^{* * *}$ & $0.42,0.62$ \\
\hline Secondary & 0.86 & $0.52,1.42$ & 1 & $0.65,1.55$ & 0.74 & $0.55,1.00$ & $0.38^{\star \star \star}$ & $0.31,0.48$ & 1.2 & $0.91,1.58$ & $0.65^{\star \star \star}$ & $0.54,0.79$ \\
\hline Higher & 1.45 & $0.81,2.57$ & $2.16^{\star *}$ & $1.34,3.47$ & $1.79^{\star \star \star}$ & $1.27,2.51$ & 0.83 & $0.63,1.08$ & $2.36^{\star \star \star}$ & $1.75,3.20$ & $1.36^{* \star}$ & $1.09,1.69$ \\
\hline \multicolumn{13}{|l|}{ Household wealth index } \\
\hline Poor & 1 & $1.00,1.00$ & 1 & $1.00,1.00$ & 1 & $1.00,1.00$ & 1 & $1.00,1.00$ & 1 & $1.00,1.00$ & 1 & $1.00,1.00$ \\
\hline Middle & 0.81 & $0.64,1.02$ & 0.89 & $0.71,1.10$ & 0.88 & $0.69,1.13$ & $0.81^{*}$ & $0.68,0.97$ & 1 & $0.84,1.19$ & 0.93 & $0.82,1.06$ \\
\hline Rich & 0.88 & $0.70,1.11$ & 0.97 & $0.78,1.22$ & 0.93 & $0.74,1.15$ & 0.92 & $0.77,1.09$ & 1.07 & $0.91,1.25$ & 0.93 & $0.81,1.05$ \\
\hline \multicolumn{13}{|l|}{ Place of residence } \\
\hline Urban & 1 & $1.00,1.00$ & 1 & $1.00,1.00$ & 1 & $1.00,1.00$ & 1 & $1.00,1.00$ & 1 & $1.00,1.00$ & 1 & $1.00,1.00$ \\
\hline Rural & $0.68^{* \star *}$ & $0.54,0.85$ & 0.95 & $0.78,1.15$ & $0.65^{\star \star \star}$ & $0.52,0.81$ & 0.92 & $0.78,1.08$ & $0.68^{\star \star *}$ & $0.59,0.79$ & 0.89 & $0.79,1.01$ \\
\hline \multicolumn{13}{|l|}{ Knowledge of contraception } \\
\hline Lack (less than 8 methods) & 1 & $1.00,1.00$ & 1 & $1.00,1.00$ & 1 & $1.00,1.00$ & 1 & $1.00,1.00$ & 1 & $1.00,1.00$ & 1 & $1.00,1.00$ \\
\hline Better (at least 8 methods) & $2.65^{\star \star *}$ & $2.13,3.28$ & $1.26^{\star *}$ & $1.08,1.49$ & $2.24^{\star \star \star}$ & $1.81,2.76$ & $1.60^{\star * *}$ & $1.39,1.85$ & $3.01^{* \star *}$ & $2.54,3.58$ & $1.55^{\star * *}$ & $1.38,1.74$ \\
\hline \multicolumn{13}{|l|}{ Fertility intention } \\
\hline Wants more children & 1 & $1.00,1.00$ & 1 & $1.00,1.00$ & 1 & $1.00,1.00$ & 1 & $1.00,1.00$ & 1 & $1.00,1.00$ & 1 & $1.00,1.00$ \\
\hline Undecided & 0.9 & $0.58,1.38$ & 0.79 & $0.53,1.17$ & $0.57^{\star}$ & $0.34,0.97$ & $0.67^{*}$ & $0.48,0.94$ & 0.82 & $0.58,1.15$ & 0.99 & $0.75,1.29$ \\
\hline Wants no more children & $0.76^{*}$ & $0.58,0.98$ & $1.95^{\star \star *}$ & $1.60,2.38$ & 0.9 & $0.71,1.13$ & $1.99^{* \star \star}$ & $1.70,2.34$ & 0.86 & $0.73,1.00$ & $1.64^{\star * *}$ & $1.45,1.86$ \\
\hline \multicolumn{13}{|l|}{ Knowledge of ovulation cycles } \\
\hline Incorrect & 1 & $1.00,1.00$ & 1 & $1.00,1.00$ & 1 & $1.00,1.00$ & 1 & $1.00,1.00$ & 1 & $1.00,1.00$ & 1 & $1.00,1.00$ \\
\hline Correct & $0.49^{\star \star *}$ & $0.40,0.60$ & 0.94 & $0.80,1.11$ & $0.60^{\star \star \star}$ & $0.50,0.72$ & $0.66^{\star \star *}$ & $0.58,0.75$ & $0.70^{\star \star \star}$ & $0.61,0.80$ & $0.82^{* * *}$ & $0.74,0.90$ \\
\hline \multicolumn{13}{|l|}{ Parity } \\
\hline $0-1$ & 1 & $1.00,1.00$ & 1 & $1.00,1.00$ & 1 & $1.00,1.00$ & 1 & $1.00,1.00$ & 1 & $1.00,1.00$ & 1 & $1.00,1.00$ \\
\hline $2-3$ & 1.02 & $0.74,1.40$ & 1.04 & $0.83,1.31$ & 0.89 & $0.69,1.15$ & 1.13 & $0.94,1.36$ & $0.78^{\star \star}$ & $0.66,0.93$ & $1.22^{* *}$ & $1.06,1.41$ \\
\hline$>3$ & 1.37 & $0.95,1.98$ & 1.18 & $0.88,1.59$ & 1.12 & $0.80,1.55$ & $1.54^{\star \star *}$ & $1.20,1.97$ & 1.21 & $0.96,1.53$ & $2.23^{\star \star *}$ & $1.85,2.68$ \\
\hline \multicolumn{13}{|l|}{ Age } \\
\hline $15-29$ & 1 & $1.00,1.00$ & 1 & $1.00,1.00$ & 1 & $1.00,1.00$ & 1 & $1.00,1.00$ & 1 & $1.00,1.00$ & 1 & $1.00,1.00$ \\
\hline $30-39$ & $1.99^{* * *}$ & $1.51,2.60$ & $2.03^{* \star *}$ & $1.61,2.56$ & $2.18^{\star \star \star}$ & $1.66,2.85$ & $1.19^{\star}$ & $1.01,1.41$ & $1.39^{* * *}$ & $1.16,1.67$ & 1.02 & $0.89,1.16$ \\
\hline $40-49$ & $3.60^{\star \star \star}$ & $2.58,5.02$ & $4.79^{\star \star \star}$ & $3.67,6.24$ & $3.84^{\star \star \star}$ & $2.79,5.28$ & $2.00^{\star \star \star}$ & $1.64,2.44$ & $2.61^{* * \star}$ & $2.13,3.19$ & $1.36^{\star \star *}$ & $1.18,1.57$ \\
\hline \multicolumn{13}{|l|}{ Region } \\
\hline Other Islands & 1 & $1.00,1.00$ & 1 & $1.00,1.00$ & 1 & $1.00,1.00$ & 1 & $1.00,1.00$ & 1 & $1.00,1.00$ & 1 & $1.00,1.00$ \\
\hline Java-Bali & $0.49^{* * *}$ & $0.40,0.59$ & $1.39^{* \star *}$ & $1.19,1.63$ & $0.41^{\star * \star}$ & $0.33,0.50$ & 1.01 & $0.87,1.17$ & $0.60^{\star \star *}$ & $0.53,0.69$ & 0.96 & $0.85,1.08$ \\
\hline
\end{tabular}

long-term methods among women who had good contraceptive knowledge also fluctuated. The odds ratio increased from 1.26 in the 2007 IDHS to 1.60 in the 2012 IDHS, then decreased to 1.55 in the 2017 IDHS.

According to this study, the proper ovulatory cycle knowledge prevented women from practicing traditional methods. After 5 and 10 years of observation, however, this trend declined. After 5 years of observation, women who understood the ovulation cycle correctly had a $40 \%$ lesser likelihood of practicing traditional methods than around $50 \%$ in the previous period. Following 10 years, correct knowledge of ovulation cycles could only prevent women from using traditional methods by about $30 \%$. An identical pattern occurred in the use of long-term methods, in which the probability that adequate knowledge of the ovulation cycle increased the likelihood of women utilizing the long-term method. The increased odds ratio in the 2012 and 2017 IDHS confirmed it.

Different patterns were observed in contraceptive use according to residential characteristics. In general, there was no significant shift during the 10 years of observation. Women living in rural areas had a significantly lower probability of using traditional methods of about $32-35 \%$. It implied that from the IDHS of 2007-2017, women in urban areas were more prone to adopt traditional methods.

Meanwhile, the 2007 IDHS showed that women who no longer wanted children were significantly less likely to use traditional contraceptives, although this pattern was no longer significant in the next 5 and 10 years. During the period 2007-2017, women in this segment had a 1.5-2 likelihood of using a longterm contraceptive method. An identical pattern was also observed in women with two or more children who tended to experience an increased pattern in the probability of using the long-term method.

There was a change in the pattern of using longterm methods according to the woman's age. In 2017 , older women were more likely to use both traditional and long-term methods. Odds ratios increased in 2012 but declined in 2017. It was critical to emphasize that traditional contraceptive users' probability was consistently greater than users of long-term methods in the segment of women who were getting older throughout the year of observation.

The contraceptive distribution pattern in Indonesia in 2007 showed that women who lived in Java and Bali had about a $50 \%$ lower probability of using traditional methods and typically tended to utilize long-term methods. After 5 and 10 years of study, however, this trend shifted. Longterm methods were no longer significantly more common among women in Java and Bali. According to the IDHS, between 2012 and 2017, the likelihood of using traditional methods in Java and Bali was growing.

\section{Discussions}

The findings showed that the pattern of contraceptive usage did not remain steady between 
periods. Nevertheless, on some factors, such as contraceptive and ovulation cycle knowledge, traditional contraceptive usage for the last decade resembled the LARC use pattern. Even though the trend fluctuated after 5 and 10 years of study, women who used both contraception types had a better understanding of contraception and the ovulation cycle than women who used short-term contraception.

It is fascinating because having a good understanding of FP and the ovulation cycle allows some women to use LARC. However, it can also encourage women to use traditional methods. These results are similar to those reported in prior research that the lack of knowledge about contraceptive methods and reproductive health has proven to be an obstacle to the use of modern contraceptives in Asia [16]. For longterm users, providing knowledge about contraceptive methods and reproductive health, especially during the fertile period, may make them aware of the importance of using modern contraception in preventing pregnancy. This result is also similar to the previous study results where long-term users are usually women who have received complete FP information [13].

For users of traditional contraception, knowing about different contraception types may increase their concern about contraception's side effects. According to a study conducted in Iran, the most common reasons given by women who use traditional contraceptives are side effects and mistrust of modern contraceptives [17]. Concerns regarding contraceptive side effects are common among women who do not support FP, where users of modern contraceptives (short-term) are usually less worried about the effects of contraception they use than those who do not use contraception [18]. When seeking information about FP, apart from being exposed to information about various contraception types, this group of women may also be exposed to information about the health effects of contraception and its rumors. The contraception effect myths are the most severe obstacle for increasing contraception use, even though the evidence is unclear [19].

Similarly, those who have better knowledge about the ovulation cycle more likely to use traditional contraception since they may believe that by arranging sexual activity according to their fertile period, they may avoid pregnancy. Thus, providing comprehensive information about FP and reproductive health is essential for women considering contraception choice. The previous study also emphasized that misinformation about reproductive health, especially the timing of pregnancy, will influence women to choose improper contraceptives [20].

As of now, women's education levels have been linked to contraceptive use, with the higher their education level, the greater their knowledge [11]. Many studies have shown that education affects contraceptive use, especially modern contraception [21], [22]. In contrast to earlier findings, however, highly educated women tend to use traditional contraceptives. These results are similar to those reported by [19], [23], [24], [25], which concluded that high levels of traditional contraceptive use among highly educated women are more closely related to the side effects of modern contraceptives than to effectiveness. It is because more educated women have better knowledge and understanding of the side effects of modern contraceptives. Besides, the level of education is associated with decision-making authority. According to a previous study, highly educated women have more control over the type of contraceptive they use [26].

Another important finding that deserved more attention was that, since the 2007 IDHS, the use of LARC continued to decrease among women with higher education. This discrepancy could be attributed to a gap between knowledge, behavior, and FP practices. It means that, despite having appropriate knowledge of modern contraceptives, women have been unable to change their contraception attitudes and practices for a long time. A possible explanation for these findings is that the decentralization of the FP program, as reported in Government Regulation No. 38/2007, resulted in various implementations in the provinces. The National Population and FP Board lost its jurisdiction over the provinces' FP program due to this regulation [27]. As a result, many regions are still unconcerned about FP programs. Another reason that may underlie this fact is the occurrence of contraceptive stock-outs in that period. Furthermore, despite undergoing an increase in the prior period, the contraceptive supply budget has decreased to just a quarter of the 2016 budget. It has consequences for reducing the prevalence of modern contraceptives by around $2.5 \%$ [28].

Older women were more likely to use both traditional and long-term methods. A probable explanation is that the focus of the FP program in Indonesia in recent years has encouraged the use of LARC. In principle, LARC is prioritized for women who are older or younger but have high parity. Prior research by [29] found different patterns in Indonesia, whether women aged 25-39 were more likely to use IUD, whereas women aged $<25$ years prefer to use hormonal contraceptives. It was also affected by the number of children owned; other findings of this study revealed that women with two or more children were more likely to use the long-term method. This result was consistent with a previous study's findings, which showed that as the number of living children grew, women were more likely to use LARC [30], [31], [32], [33].

Older women more commonly use traditional contraceptives, possibly because they have more contraception experience, even if they have had side effects. As a result, they feel more comfortable and acceptable with traditional contraceptives. These results are similar to those reported by [34] that women who have experienced side effects or health problems due to contraceptive use will prefer to stop using 
these contraceptives. Besides, older women may feel that they are already infertile, so they prefer to use traditional methods [35], [36], [37]. Another factor is that older women have less sexual libido [38]. It is worrying because many women's infertility assumptions are often incorrect, putting them at risk of an unwanted pregnancy.

There was no significant shift during the 10 years of observation; women who lived in urban areas and those in Java and Bali were more likely to use traditional methods. The finding is identical to previous studies; urban women in Indonesia and the Philippines have a higher percentage of traditional method use than rural residents [39]. It seems possible that these results are due to the fact that the traditional method, however, is associated with the identity of a "disciplined, educated, and modern" woman [40], which is representative of women in an urban community. Since contraceptives have been subsidized and provided for free by the government from 1976, clients were only responsible for the cost of services, which increased public demand for the commodities [41]. Additionally, the national health insurance policy requires the government to provide contraceptive commodities as part of its mandated health services [42]. These factors may account that the wealth index has no significant effect on access to contraceptive services.

The repeated cross-sectional research design, which uses variables that are evaluated using the same questionnaires and sampling techniques over the study period, generously provides robustness to the empirical findings, as does the proper use of large, nationally representative datasets. The pooled regression used in this study provides time effect estimates by enabling interaction between time dummy variables.

Even though the study has these notable advantages, it also has shortcomings. All of the data are self-reported, making it susceptible to recall bias. Analyzing variables from different levels at one ordinary level using the standard logistic regression model could create bias due to the correlation between individuals within the same community. However, the multilevel model should be performed to investigate the extent of the relationships between different individual-level and community-level variables related to contraceptive use.

\section{Conclusion}

The trend of contraceptive use in Indonesia has shifted over the three periods of the IDHS. The short-term method dominated contraceptive use. LARC and traditional methods users, on the other hand, progressively increased over the three observation periods. Various sociodemographic variables produced a substantial impact on contraceptive use between
2007 and 2017. In general, the probability of using traditional methods driven by the improvement of education, knowledge of contraception and fertility, and modernization represented by urban areas increased, exceeding the probability of using long-term methods from year to year. It typically implies that contraceptive use determinants are always dynamic over time; therefore, FP strategies and policies should adapt accordingly. Giving an understanding of contraceptive methods' benefits and risks through adequate method information is encouraged to prevent contraceptive dropout or switch to less-effective methods. The most up-to-date and robust modeling strategies are required to achieve more considerable accuracy.

\section{Acknowledgment}

The authors are grateful to MEASURE DHS for access to the Indonesian datasets. The authors also wish to acknowledge Professor Aris Ananta and Dr. Sudibyo Alimoesoe for the valuable feedback on this manuscript and the Indonesian Population and FP Board (BKKBN) for supporting this work by funding research grants.

\section{References}

1. Yaya S, Uthman OA, Ekholuenetale M, Bishwajit G. Women empowerment as an enabling factor of contraceptive use in Sub-Saharan Africa: A multilevel analysis of cross-sectional surveys of 32 countries. Reprod Health. 2018;15:214. https:// doi.org/10.1186/s12978-018-0658-5

PMid:30572927

2. Fabic MS, Choi Y, Bongaarts J, Darroch JE, Ross JA, Stover J, et al. Meeting demand for family planning within a generation: The post-2015 agenda. Lancet. 2015;385(9981):1928-31. https://doi.org/10.1016/S0140-6736(14)61055-2 PMid:24993915

3. Petruney T, Wilson LC, Stanback J, Cates W. Family Planning and the Post-2015 Development Agenda. Bull World Health Organ. 2014;92(8):548-A. https://doi.org/10.2471/BLT.14.142893 PMid:25177066

4. Festin MP, Kiarie J, Solo J, Spieler J, Malarcher S, van Look PF, et al. Moving towards the goals of FP2020-classifying contraceptives. Contraception. 2016;94(4):289-94. https://doi. org/10.1016/j.contraception.2016.05.015 PMid:27287693

5. Kistiana S, Gayatri M, Sari DP. Determinants of modern contraceptive use among young married women (age 15-24) in Indonesia. Glob J Health Sci. 2020;12:37.

6. Alyahya MS, Hijazi HH, Alshraideh HA, Al-Sheyab NA, Alomari D, Malkawi $\mathrm{S}$, et al. Do modern family planning methods impact women's quality of life? Jordanian women's perspective. Health Qual Life Outcomes. 2019;17(1):154. https://doi.org/10.1186/ s12955-019-1226-6 


\section{PMid:31615524}

7. Gayatri M, Utomo B. Contraceptive method use in Indonesia: Trends and determinants between 2007, 2012 and 2017. Indian J Public Health Res Dev. 2019;10(12):1818-23.

8. PMA2020. PMA2015/Indonesia-R1 Performance Monitoring and Accountability 2020; 2015.

9. Samosir OB, Kiting AS, Aninditya F. Role of information and communication technology and women's empowerment in contraceptive discontinuation in Indonesia. J Prev Med Public Health. 2020;53(2):117-25. https://doi.org/10.3961/ jpmph.19.300

PMid:32268466

10. Statistics Indonesia; National Population and Family Planning Board; Ministry of Health; USAID. Indonesian Demographic and Health Survey 2017, Jakarta; 2018.

11. Efendi F, Gafar A, Suza DE, Has EM, Pramono AP, Susanti IA. Determinants of contraceptive use among married women in Indonesia. F1000Res. 2020;9:193. https://doi.org/10.12688/ f1000research.22482.1

PMid:32269768

12. Idris $\mathrm{H}$. Factors affecting the use of contraceptive in Indonesia: Analysis from the national socioeconomic survey (susenas). J Kesehatan Masyarakat. 2019;15:117-23.

13. Mahendra IG, Wilopo SA, Sukamdi, Putra IG. The role of decision-making pattern on the use of long-acting and permanent contraceptive methods among married women in Indonesia. Eur J Contracept Reprod Health Care. 2019;24(6):480-6. https://doi. org/10.1080/13625187.2019.1670345 PMid:31566414

14. Amran Y, Nasir NM, Dachlia D, Yelda F, Utomo B, Ariawan I, et al. Perceptions of contraception and patterns of switching contraceptive methods among family-planning acceptors in West Nusa Tenggara, Indonesia. J Prev Med Public Health. 2019;52(4):258-64. https://doi.org/10.3961/jpmph.18.198 PMid:31390689

15. Rahardja MB. Family planning service quality and contraceptive change in Indonesia. Kesehatan Masyarakat Nasl. 2007;6:140-4.

16. Najafi-Sharjabad F, Yahya SZ, Rahman HA, Juni MH, Manaf RA. Barriers of modern contraceptive practices among Asian women: A mini literature review. Glob J Health Sci. 2013;5(5):181-92. https://doi.org/10.5539/gjhs.v5n5p181 PMid:23985120

17. Asadi Sarvestani K, Ahmadi A, Enayat H, Mo-Vahed M. Level and factors related to unintended pregnancy with a brief review of new population policies in Iran. Iran J Public Health. 2017;46(7):973-81 PMid:28845409

18. Mansour D. International survey to assess women's attitudes regarding choice of daily versus nondaily female hormonal contraception. Int J Womens Health. 2014;6:367-75. https://doi. org/10.2147/IJWH.S59059

PMid:24729734

19. Darroch JE, Sedgh G, Ball H. Contraceptive Technologies: Responding to Women's Needs. New York, United States: Guttmacher Institute. 2011. p. 1-51.

20. Gadow EC, Jennings VH, López-Camelo JS, Paz JE, da Graça Dutra M, Leguizamón G, et al. Knowledge of likely time of ovulation and contraceptive use in unintended pregnancies. Adv Contracept. 1999;15(2):109-18. https://doi. org/10.1023/a:1006793509084

PMid:10997893

21. Adanu RMK, Seffah JD, Hill AG, Darko R, Duda RB, Anarfi JK. Contraceptive use by women in Accra, Ghana: Results from the 2003 Accra Women's health survey. Afr J Reprod Health. 2009;13(1):123-33.

\section{PMid:20687270}

22. Eisenberg DL, Secura GM, Madden TE, Allsworth JE, Zhao Q, Peipert JF. Knowledge of contraceptive effectiveness. Am J Obstet Gynecol. 2012;206(6):479.e1-9. https://doi. org/10.1016/j.ajog.2012.04.012 PMid:22521458

23. Ram F, Shekhar C, Chowdhury B. Use of traditional contraceptive methods in India and its sociodemographic determinants. Indian J Med Res. 2014;140 Suppl 1:S17-28.

PMid:25673538

24. Erfani A, Yuksel-Kaptanoglu I. The use of withdrawal among birth limiters in Iran and Turkey. Stud Fam Plann. 2012;43(1):2132. https://doi.org/10.1111/j.1728-4465.2012.00299.x PMid:23185869

25. Basu AM. Ultramodern contraception. Asian Popul Stud. 2005;1:303-23

26. Wilson EK, Koo HP. Associations between low-income women's relationship characteristics and their contraceptive use. Perspect Sex Reprod Health. 2008;40(3):171-9. https://doi. org/10.1363/4017108

PMid: 18803799

27. Hull TH, Mosley H. Revitalization of Family Planning in Indonesia; 2009.

28. Ardiana I, Ekoriano M, Fathonah S. Universal health coverage 2019 in Indonesia: The integration of family planning services in current functioning health system. J Popul Soc Stud. 2019;27:247-65.

29. Jones J, Mosher W, Daniels K. Current contraceptive use in the united states, 2006-2010, and changes in patterns of use since 1995. In: Sexual Statistics: Select Reports from the National Center for Health Statistics, Maryland; 2013. p. 127-73.

30. Ajong AB, Njotang PN, Kenfack B, Essi MJ, Yakum MN, Iballa FB, et al. Contraceptive method mix and preference: $A$ focus on long acting reversible contraception in Urban Cameroon. PLoS One. 2018;13(8):e0202967. https://doi.org/10.1371/journal. pone.0202967

PMid:30138474

31. Tebeje B, Workneh D. Prevalence, Perceptions and Factors Contributing to Long Acting Reversible Contraception Use among Family Planning Clients, Jimma Town, Oromiya Region, South-West Ethiopia; 2017.

32. Melka AS, Tekelab T, Wirtu D. Determinants of long acting and permanent contraceptive methods utilization among married women of reproductive age groups in Western Ethiopia: A cross-sectional study. Pan Afr Med J. 2015;21:246. https://doi. org/10.11604/pamj.2015.21.246.5835 PMid:26523185

33. Teferra AS. Determinants of long acting contraceptive use among reproductive age women in Ethiopia: Evidence from EDHS 2011. Sci J Public Health. 2015;3:143.

34. Vessey M, Yeates D, Flynn S. Factors affecting mortality in a large cohort study with special reference to oral contraceptive use. Contraception. 2010;82(3):221-9. https://doi.org/10.1016/j. contraception.2010.04.006 PMid:20705149

35. Withers M, Kano M, Pinatih GN. Desire for more children contraceptive use and unmet need for family planning in a remote area of Bali, Indonesia. J Biosoc Sci. 2010;42(4):54962. https://doi.org/10.1017/S0021932010000052 PMid:20202273

36. Cindoglu D, Sirkeci I, Sirkeci RF. Determinants of choosing withdrawal over modern contraceptive methods in Turkey. Eur $J$ Contracept Reprod Health Care. 2008;13(4):412-21. https://doi. org/10.1080/13625180802255719

PMid:19117258 
37. Almalik M, Mosleh S, Almasarweh I. Are users of modern and traditional contraceptive methods in Jordan different? Eastern Mediterr Health J. 2018;24(4):377-84. https://doi. org/10.26719/2018.24.4.377 PMid:29972232

38. MacKay J. Global sex: Sexuality and sexual practices around the world. Sex Relat Ther. 2001;16:71-82.

39. Gebreselassie T, Bietsch K, Staveteig S, Pullum T. Trends, Determinants, and Dynamics of Traditional Contraceptive Method Use, DHS Analytical Studies; 2017. p. 9.
40. Johnson-Hanks J. On the modernity of traditional contraception: Time and the social context of fertility. Popul Dev Rev. 2002;28(2):229-49.

41. Teplitskaya L, Ross R, Dutta A. Has Indonesia's National Health Insurance Scheme Improved Family Planning Use? Washington DC: Palladium, Health Policy Plus; 2018.

42. Sulistiawan D, Lazuardi L, Fanda RB, Asrullah M, Matahari $R$, Arifa RF. Who experience out-of-pocket expenditures for modern contraceptive use in indonesian universal health coverage system? Med Legal Update. 2021;21:193-200. 